\title{
Representações de beleza de mulher no jornal Folha do Norte do Paraná: modelos de feminilidades nos anos 1960 .
}

\author{
Woman beauty representations in the newspaper Folha do Norte do \\ Paraná: models offemininities in the 1960s.
}

\author{
Ivania Skura** \\ Cristina Satiê de Oliveira Pátaro*** \\ Frank Antonio Mezzomo**:**
}

RESUMO

Neste artigo, o jornal Folha do Norte do Paraná é tanto fonte como objeto de pesquisa. São buscadas representações de beleza de mulher presentes no período que compreende os anos de 1962 a 1964 . Ao analisar tal periódico, fundado pela Igreja Católica da diocese de Maringá/PR, busca-se compreender, a partir deste recorte regional, as construções socioculturais históricas do espaço da mulher na sociedade norte paranaense. Foram elencadas matérias da coluna denominada Folha Feminina, espaço desta mídia impressa que fala diretamente para as mulheres. As dicas, conselhos e apelos de beleza presentes em tais conteúdos são permeados por valores, normas e comportamentos que intentaram delinear feminilidades à época. Ao mesmo tempo, as representações identificadas evidenciam nuances e transformações em relação aos modelos hegemônicos, sugerindo influências da dinâmica social que caracterizou o período.

Palavras-chave: Mulher. Gênero. História. Jornal. Igreja Católica.

\footnotetext{
* Este artigo é vinculado a pesquisa que contou com apoio do Conselho Nacional de Desenvolvimento Científico e Tecnológico, CNPq, Brasil. Agradecemos ainda o apoio da Coordenação de Aperfeiçoamento de Pessoal de Nível Superior, CAPES, Brasil.

${ }^{*}$ Doutoranda no Programa de Pós-Graduação em Comunicação e Linguagens da Universidade Tuiuti do Paraná. Mestre em Sociedade e Desenvolvimento, pela Universidade Estadual do Paraná e Graduada em Comunicação Social pelo Centro de Ensino Superior de Maringá. E-mail: ivaniaskura@hotmail.com

${ }^{* * *}$ Professora do Programa de Pós-Graduação Interdisciplinar Sociedade e Desenvolvimento e do Mestrado Profissional em Ensino de História da Universidade Estadual do Paraná, câmpus de Campo Mourão. Doutora em Educação e Bolsista Produtividade pela Fundação Araucária. E-mail: crispataro@gmail.com

${ }^{* * * *}$ Professor do Programa de Pós-Graduação Interdisciplinar Sociedade e Desenvolvimento e do Mestrado Profissional em Ensino de História da Universidade Estadual do Paraná, câmpus de Campo Mourão. Doutor em História, Líder do Grupo de Pesquisa Cultura e Relações de Poder e Editor da Revista NUPEM. E-mail: frankmezzomo@gmail.com
} 


\section{ABSTRACT}

In this paper, the newspaper Folha do Norte do Paraná is both source and object of research. Woman beauty representations were sought in the period comprising the years 1962-1964. In analyzing such press, founded by Catholic Church (Diocese of Maringá/PR), it is aimed to understand, from this regional level, the historical sociocultural constructions of woman space in the northern Paraná society. It was listed reports of the column named Folha Feminina, space from this print media that speaks directly to women. The tips, advices and beauty appeals present in the matters are permeated by values, norms and behaviors that intended to delineate femininity at the time. Simultaneously, the identified representations show nuances and changes in relations to hegemonic models, suggesting influences from social dynamic of the studied period.

Keyword: Woman. Gender. History. Newspaper. Catholic Church.

\section{Introdução}

O objetivo deste trabalho é identificar as representações ${ }^{1}$ de beleza de mulher veiculadas em um meio de comunicação que é tanto fonte quanto objeto de estudo: o jornal impresso Folha do Norte do Paraná (FNP), periódico fundado pela Igreja Católica, diocese de Maringá/PR, em 1962. A pesquisa surgiu da inquietação em compreender, a partir de um recorte regional, construções socioculturais históricas do espaço da mulher na sociedade paranaense, em uma perspectiva que contemple os estudos de gênero como lente conceitual. Compreendemos a análise das representações da mulher presentes nas páginas do jornal como uma tarefa interdisciplinar, ao passo que envolve conceitos-chave provindos de diversas áreas do conhecimento, tais como: a história, a educação, a comunicação, além de outros campos fronteiriços a estes, como a arquivologia, a antropologia e a sociologia.

As discussões acerca da história das mulheres e das relações de gênero, da mesma maneira, envolvem um processo de construção histórica, social, política e econômica de feminilidades e de relações de poder constituídas, que ultrapassam abordagens disciplinares. Assim, os estudos que propõem a abordagem do feminino "Apóiam-se em outras disciplinas - tais como a literatura, a lingüística, a psicanálise e, principalmente, a antropologia -, com o intuito de desvendar as diversas dimensões desse objeto. Assim, a

\footnotetext{
${ }^{1}$ Neste espaço da significação, as representações devem ser entendidas como formas de classificar e de perceber, como instituições sociais, as quais denotam divisões da organização social e práticas que constroem o próprio mundo social (CHARTIER, 1991).
} 
interdisciplinaridade assume importância crescente nos estudos sobre as mulheres" (SOIHET; PEDRO, 2007, p. 295).

Os estudos de gênero discutem desigualdades entre o feminino e o masculino, compreendendo que as mesmas são construídas em determinados momentos históricos e sociedade, e abandonando determinismos biológicos e modelos de conduta préestabelecidos. Questionar os "naturalizados" papéis de gênero, que frequentemente desvalorizam uma parte em função da outra, é componente da busca pela igualdade que envolve a mudança de noções engendradas em representações bastante sexistas que foram se consolidando historicamente. Lembra Pinsky que,

Quando falamos em gênero, estamos falando da construção cultural do que é percebido e pensado como diferença sexual, ou seja, das maneiras como as sociedades entendem, por exemplo, o que é 'ser homem' e 'ser mulher', e o que é 'masculino' e 'feminino'. Assim, podemos tratar essas noções como conceitos históricos [...] encarados como concepções produzidas, reproduzidas, mas também transformadas ao longo do tempo, que podem variar em cada contexto social. (PINSKY, 2014, p. 11).

Nesse movimento, ao problematizar as relações de gênero, pretendemos identificar os discursos2 do jornal Folha do Norte do Paraná (FNP) que permearam as noções de beleza feminina vigentes na primeira metade da década de 1960, em especial nos anos de 1962 a 1964.

Para trabalhar com o FNP, analisando e evidenciando de modo sistemático esse corpus documental, foi preciso delimitar o estudo do objeto. Dessa maneira, ao elencar a representação da mulher como elemento problemático do estudo, decidiu-se por enfocar as matérias diretamente voltadas ao público-alvo mulher3, produzidas, em grande parte, por jornalistas mulheres. Trata-se da Folha Feminina, presente no FNP.

A Folha Feminina é a única seção do FNP que fala direta e explicitamente para as mulheres e, em vista da quantidade de matérias encontradas - um total de 224 -, foi necessário estreitar o corpus de modo a aprofundar as análises. Especificamente no período

\footnotetext{
2 “Chama-se geralmente discurso, na prática das análises, toda a comunicação estudada, não só ao nível de constituintes elementares (a palavra, por exemplo) mas também e sobretudo a um nível igual e superior à frase (proposições, enunciados, sequências)" (BARDIN, 2011, p. 217).

${ }^{3}$ Destaca-se que, no contexto tratado, quando se fala de "mulher", as mensagens dirigiam-se geralmente às mulheres brancas, com determinada capacidade de consumo e estilo de vida. Discussões sobre marcadores sociais de diferenças que envolvem raça/etnia e classe social, embora não sejam foco desta investigação e não sejam aqui contempladas, podem enriquecer a problematização do tema em questão.
} 
que compreende os anos de 1962-1964 (recorte temporal), visou-se, assim, identificar representações que abarcam o tema da beleza (recorte temático), categoria mais representativa dentre as matérias publicadas.

O período analisado engloba os primeiros anos da fundação, disseminação e fortalecimento da mídia impressa investigada - que se iniciou em 1962, com a primeira edição do jornal -, permitindo uma análise das possíveis influências de diversos movimentos, forças e relações que permeavam o período. Nesse momento - início da década de 1960 -, em âmbito internacional, podemos mencionar o movimento da contracultura, que se opôs aos princípios de uma sociedade conservadora; a intensificação dos movimentos feministas, ocorrida ao longo da década de 1960; o Concílio do Vaticano II, movimento vinculado à Igreja Católica e realizado entre os anos de 1962 e 1965. Já em nível nacional, destacam-se a industrialização e modernização do Brasil nos anos 1960; a publicação do Estatuto da Mulher casada (lei homologada pela Presidência da República em 1962); a definição do Marco Regula tório dos Meios de Comunicação (1963); a realização, em boa parte do território nacional, das Marchas da Família com Deus pela Liberdade (1964), entre outros acontecimentos.

No contexto brasileiro, o recorte temporal de 1962 a 1964 denota, ainda, uma fase de transição de um governo democrático para a instabilidade política protagonizada pelo regime militar, em 1964 e, em uma visão mais regional, permite notar modificações no cenário econômico em especial no norte do Paraná, em processo de urbanização e industrialização.

No processo de análise das matérias do jornal, a importância de contextualizar suas condições de produção vem da necessidade de discutir não só o que está apresentado nas páginas desta mídia impressa, mas como está sendo representado, para denotar as relações de poder e significados identitários dos quais ele é porta-voz.

Fundada oficialmente em 1947, o município de Maringá passa a ser sede episcopal em fevereiro de 1956, sob o pontificado de Pio XII, tendo como primeiro bispo Dom Jaime Luiz Coelho (ROBLES, 2007). A institucionalização de uma diocese possibilitou a construção de uma identificação sociocultural eclesiástica regional (GARUTTI, 2013) e, na história da Igreja Católica no Brasil, Maringá obteve destaque, uma vez que era, até então, a cidade mais jovem que havia recebido um bispo e sido elevada à categoria de diocese (RUBINO, 2010).

O bispo foi o responsável pela estruturação inicial do FNP, em 1961, que ocorreu a partir da venda de ações, quando foram adquiridos os primeiros equipamentos e começou a ser recrutada a equipe de trabalho, de modo que em setembro de 1962, veio a público a primeira edição do novo jornal. 
Dois anos depois da fundação do jornal, com poucos recursos para modernizar a estrutura, e diante de uma situação financeira frágil, Dom Jaime arrendou o FNP. Mesmo que a posse do jornal não fosse mais da diocese, o bispo tinha ainda forte influência no veículo de comunicação e membros da Igreja ainda ocupavam sua estrutura administrativa. Em 1977, Dom Jaime retomou a posse do FNP e iniciou um pedido de fechamento do jornal, de modo que em 1979, encerrou a circulação desta mídia impressa (PAULA, 2009) ${ }^{4}$.

Na década de 1960, um jornal do porte do FNP significava muito. O processo técnico era dificultoso e envolvia diversas fases com limitações técnicas e financeiras. No cenário regional e nacional, eram raras as cidades que não fossem capitais possuir jornais como o FNP. Mudanças no formato foram ocorrendo conforme ele se consolidava na região. No final de 1964, com uma tiragem de cerca de 7.000 exemplares, esteve em circulação em mais de 90 cidades, abrangendo sobretudo capelas, paróquias e dioceses, entre elas as de Campo Mourão, Paranavaí e Umuarama, pertencentes à Província Eclesiástica de Maringá, além de sucursais em capitais como Curitiba, São Paulo e Florianópolis.

O FNP, em todo o período em que circulou, podia ser caracterizado como jornal de temática livre, por possuir colunas com teor informativo, anúncios, propagandas, notícias, reportagens, opiniões, entre outras (SILVA; FRANCO, 2010). Começou a vender espaço publicitário já em 1962, e muitas das maiores empresas da cidade e região anunciavam no jornal. O estudo com base no FNP se justifica pela relevância que tal veículo impresso assumiu em toda a região. No período estudado por esta investigação, suas oito colunas de texto em meio a boxes azuis, chamadas e anúncios de publicidade acomodaram uma infinidade de conteúdo passível de análise.

\section{Os caminhos da pesquisa}

No FNP, referências à mulher apareciam com frequência nas colunas sociais, destacando a presença de mulheres e tecendo comentários sobre suas vestimentas, comportamentos e corpo. Além disso, concursos de beleza feminina - nacionais e internacionais - eram noticiados com regularidade. Matérias em outros espaços fizeram referências à participação da mulher no campo profissional, por exemplo, evidenciando campos de trabalho geralmente associados ao sexo feminino, denotando que a mulher recebia destaque principalmente como professora, responsável por ensinar as crianças, ou

\footnotetext{
${ }^{4}$ A atuação de Dom Jaime na imprensa regional não acabou, já que o bispo continuou publicando textos no jornal $\mathrm{O}$ Diário do Norte do Paraná. Robles (2007) ainda denota que antes, em junho de 1968, havia sido obtida, em Maringá, a primeira concessão de um canal de televisão para a cidade, momento em que foi criada a TV Cultura de Maringá, afiliada à Rede Globo de Televisão a partir de 1978. Dom Jaime Luiz Coelho fazia parte da diretoria do referido canal.
} 
doméstica $^{5}$. De um modo geral, as representações de mulher que apareciam no FNP - em reportagens, propagandas, anúncios e mesmo em colunas religiosas publicadas pelo periódico - reforçavam o modelo hegemônico sustentado pelos papéis de mãe, esposa e dona do lar (PÁTARO; MEZZOMO; RIBEIRO, 2014; PÁTARO; MEZZOMO; SILVA, 2014; SKURA; PÁTARO; MEZZOMO, 2015).

A escolha da Folha Feminina deu-se, principalmente, por esta seção falar diretamente para as mulheres. Embora fosse sabido da participação editorial feminina na escrita da coluna (conforme menção em outros espaços do jornal), muitas matérias não continham informação de autoria. No corpus aqui tratado, os conteúdos publicados no primeiro ano não identificavam a autora. Em 1963, Leonice Boamorte assinou boa parte das matérias e, em 1964, algumas das publicações foram assinadas por Eda Coutinho Barbosa.

A Folha Feminina era composta por duas ou mais matérias, algumas ilustradas, geralmente localizada na página 6 ou 7, e costumava ocupar cerca de um quarto da página, alocando-se na parte inferior direita até março de 1963 e, a partir desse período, na parte superior direita ${ }^{6}$. Em alguns períodos, a coluna foi publicada diariamente e, em outros, semanalmente, em geral nas quintas-feiras. Considerando o recorte temporal proposto, foram localizadas 40 matérias em 1962, 104 em 1963 e 80 em 1964.

Percebeu-se que a Folha Feminina do FNP com frequência abordou temas que seguem um padrão que pode ser notado também em outros periódicos da época. Pinsky aponta que o universo de assuntos destinados ao público feminino, principalmente nos Anos Dourados (1945-1964), era composto por reportagens sobre "casamento, filhos, moda, beleza, culinária, prendas domésticas, decoração, crônica social, etiqueta e 'matérias de comportamento" (PINSKY, 2014, p. 23). Do mesmo modo, Buitoni, ao analisar a imprensa feminina desde os anos 1800 até a atualidade, indica que "os temas tradicionais da imprensa feminina resumem-se a meia dúzia de itens: moda, beleza, culinária, decoração, comportamento, celebridades, um conto etc." (BUITONI, 2009, p. 25).

Dentro de uma linha editorial que identificamos como aproximadamente linear e reiteradora de discursos bastante parecidos, escolhemos explorar a categoria beleza, já que nela enquadraram-se 89 das 224 matérias inicialmente identificadas. Nelas, o tema dos cuidados com a Pele aparece em 53 momentos; menciona-se sobre Maquiagem 26 vezes e

\footnotetext{
${ }^{5}$ Com raras exceções, e sempre tratadas como fora do comum, na história de Maringá se apresentam algumas mulheres que se sobressaíram no mundo público assumindo funções mais próximas da maternidade e da educação, como professoras, enfermeiras e bibliotecárias (TAIT, 1999).

${ }^{6}$ Com este formato, a coluna existiu entre 1962 e 1966. No ano de 1965 não houve publicações e, entre 1967 e 1968, a coluna foi renomeada como Folha da Mulher. Em 1969, existiram três colunas femininas no FNP: Sua Excelência a Mulher, Mulheres em Evidência e Assunto de Mulher. Em1970 e 1971, a coluna feminina não fez parte do jornal. No ano de 1972, poucas reportagens foram publicadas, mas o nome Folha Feminina passa a ser usado novamente e perdurou até 1979, quando o jornal saiu de circulação. No ano de 1974 também existiu a coluna Mulher e, em 1975 e 1976, não foram publicadas colunas femininas. Uma edição especial do FNP, homenageando mulheres de destaque da região, foi publicada com o título Personalidades Femininas em 1978.
} 
sobre Cabelo, 24. A temática Corpo está presente em 16 publicações no período. 13 matérias fazem uso do argumento da Saúde ao falar de beleza e 10 dão dicas de Condutas que supostamente tornam a mulher mais bela. Em 2 matérias, trata-se especificamente sobre cuidados com as Unhas e outras 2 abordam o embelezamento feminino por meio da Cultura. Vale ressaltar que um mesmo conteúdo pode ser enquadrado em mais de uma categoria.

A análise de conteúdo permitiu que fosse explorada a empiria com apoio de técnicas específicas, ainda que estas não fossem doutrinais, ou mesmo normativas (BARDIN, 2011). Assim, na análise das matérias, observou-se: a regra da exaustividade, em que todos os elementos foram consultados, explorados e conhecidos; a regra da representatividade, pela qual efetuamos o estudo com base em uma amostra representativa do universo inicial; a regra da homogeneidade, que permite que em universos mais similares, amostras menores sejam aceitáveis e representativas; e, por fim, a regra de pertinência, a qual constata que os documentos devem ser adequados e selecionados enquanto fonte de informação visando conformar-se ao objetivo que incentivou a análise.

Optamos por trazer a análise apoiada em dois grandes eixos de discussão: 1) A beleza como recorte temático e 2) A bela mulher que trabalha fora. O primeiro eixo de análise denota de que forma, na Folha Feminina do FNP, a beleza se mostra como característica constitutiva dos discursos. O segundo eixo aborda discursos que refletem mudanças nos modelos rígidos de feminilidade, apontando, ainda que dentro do apelo homogeneizante dos cuidados estéticos, novos espaços sociais das e para as mulheres na década de 1960.

\section{A beleza como recorte temático: uma representaçãolegítima}

Ao falar de beleza, o conceito incorpora do pelo estudo e ao qual nos referimos é ligado diretamente às noções de aparência do corpo. As exigências da beleza feminina, muitas vezes, aparecem como compulsórias e a "boa aparência" se instala como atributo fundamental feminino nas mensagens, talvez porque, historicamente, desenvolveu-se a crença na relação de causa e efeito entre a aparência e o caráter dos indivíduos, aspecto bastante valorizado na sociedade e que se alinha aos valores cristãos que estão no pano de fundo do FNP.

O ideal grego da perfeição, com justa proporção e simetria, era expresso pela Kallokagathia, termo que nasce da palavra Kállos (traduzida como "belo") e da palavra Agathós (traduzida como "bom") (BARROS, 2013). Por isso, uma pessoa bela seria também considerada como digna, corajosa e com habilidades morais. Courtine e Haroche (1988) já 
denotavam que o caráter, lido no rosto do indivíduo, mostra como a aparência é produzida como efeito de um eu profundo, do interior pessoal. Nesta mesma direção, demonstrando como a associação entre boa aparência e boa índole frequentemente é feita, Eco explica que:

"belo" - junto com "gracioso", "bonito" ou "sublime", "maravilhoso", "soberbo" e expressões similares - é um adjetivo que usamos frequentemente para indicar algo que nos agrada. Parece que, nesse sentido, aquilo que é belo é igual a aquilo que é bom e, de fato, em diversas épocas históricas criou-se um laço estreito entre o Belo e o Bom. (ECO, 2004, p. 8).

Se a ideia predominante é a de que o feminino se expressa principalmente por meio da aparência, na década de 1960 esse discurso se traduzia em publicações com incansáveis conselhos práticos às mulheres, de modo que, nesse período, "traumas e frustrações tornaram-se termos comuns nos conselhos de beleza" (SANT'ANNA, 2012, p. 119). O embelezamento era encarado com certa complicação e as exigências eram diversas. Manter belo o rosto, as mãos, o corpo, e a postura elegante, eram tarefas dignas de manuais e conselhos diários para as mulheres.

Ao observar os argumentos que afirmam a necessidade dessas práticas, trazidos pelas matérias da Folha Feminina do FNP, podemos avaliar, sem dúvidas, que a construção do corpo feminino se constitui como um mediador de relações sociais de gênero (ALVES, 2014), já que nem sempre a beleza feminina servia para a mulher sentir-se bela, mas para parecer bela ao outro. Do mesmo modo, nesta lógica, infere-se que a própria constituição do ser mulher se dá na/pela mediação do outro (BEAUVOIR, 1980), sendo a relação da mulher com a estética do corpo e o olhar do outro um enlace visível (VILHENA; MEDEIROS, 2005).

A matéria da Folha Feminina intitulada "A beleza antes de tudo" ensina: "É o seu dever ser bela, para que os seus filhos e o seu marido sintam-se sempre orgulhosos de você. Para consegui-lo bastam um pouco de vontade, método e engenhosidade" (Folha do Norte do Paraná, A beleza antes de tudo, 22 mar. 1964, p. 6.). Esse conteúdo representa o discurso recorrente encontrado no FNP, o imperativo social de que ser mulher é buscar um ideal de beleza e a aprovação social masculina.

Já desde o início do século $\mathrm{XX}$, as virtudes constituintes da feminilidade costumam pautar-se em características como recato, docilidade, afetividade mais desenvolvida e receptividade passiva relacionada aos desejos e necessidades masculinas e também dos 
filhos (ALMEIDA, 2012). As cobranças em torno da postura, dos sapatos, da maquiagem, da beleza da pele e dos cabelos, assim como do agir, mostram uma exigência em relação ao aparecer/apresentar-se. Na década de 1960, partindo do referido jornal como exemplo da representação midiática, já é possível concluir que há um imperativo social de íntima ligação entre mulher e beleza.

É válido o questionamento dessas representações, uma vez que há uma relação na qual o corpo feminino se caracteriza como uma espécie de patrimônio capital cultural que supera outras características constituintes do sujeito mulher, na qual ganha destaque a busca por uma boa apresentação, cenário em que as roupas e acessórios da moda, o corpo belo e jovem, a boa forma e outros valores constituintes da feminilidade não são apenas abordados com destaque, mas se apresentam como definidores da identidade das mulheres, moldando corpos, gestos, condutas, gostos, desejos e expectativas.

A matéria da Folha Feminina intitulada "Afinal como ser bela?" afirmava: "Não existe um tipo de beleza ideal, toda mulher traz em si uma promessa de beleza [...] Para conservar a sedução não é suficiente ser apenas bela, é necessário o charme, a malícia, e, sobretudo o espírito" (Folha do Norte do Paraná, Afinal como ser bela?, 17 abr. 1964, p. 5). Nota-se um discurso que articula argumentos de modo a afirmar que o esforço dirigido à busca pela beleza não só dependia das aparências, mas também dos modos de se portar.

A publicação "Maneiras à mesa" (Folha do Norte do Paraná, 3 jul. 1964, p. 6) aconselha às mulheres que possuam "verniz" social observarem: corrigir atitudes vistas como não educadas de cônjuges, nunca se servir primeiro, iniciar a refeição só depois que todos estejam servidos, não convidar as crianças à mesa quando houver visitas, limpar a boca antes de tomar bebidas, posicionar o guardanapo estendido no colo e colocá-lo ao lado do prato ao fim da refeição.

As considerações de Del Priore auxiliam a compreender esses apelos, quando a autora denota que a coquetteire (valorizar-se para agradar, cuidar da maquiagem, pele e cabelo, andar e gesticular graciosamente) era considerada como a mais admirável qualidade da mulher, fazendo as feias parecerem bonitas e as bonitas, encantadoras (DEL PRIORE, 2009). A coquetteire é "literalmente a preocupação de se valorizar para agradar" (DEL PRIORE, 2014a, p. 114). Alves (2014) também aborda o coquetismo (ou coqueteria), apontando que este se estabelece como forma de sedução, de despertar o interesse do outro.

Courtine e Haroche (1988) apontam que, historicamente, o corpo, a aparência, a boa presença e a postura devem harmonizar até mesmo com a linguagem, já que o cuidado com a expressão demonstra "civilidade". Sant'anna (2012), da mesma forma, comenta que a beleza vai além da aparência, de modo que desde a década de 1950, além de dicas para melhorar a beleza, indicava-se como era esperado que as mulheres se comportassem, de 
forma que os conselhos atentavam para a importância de saber andar, sentar, dançar e conversar "adequadamente". A Folha Feminina ainda postulava:

Toda mulher pode tornar-se elegante e bela pois não existe somente a beleza dos traços, mas também a da postura, do corpo bem proporcionado, da alma que se reflete no rosto muito mais do que a maioria das pessoas pensa. A beleza na graça, do andar, a simpatia etc. (Folha do Norte do Paraná, Para sua beleza, 3 jul. 1964, p. 6).

Culturalmente, a mulher é receptora de noções que reiteram a insegurança quanto à aparência (WOLF, 1992). O julgamento de si mesma e de outras mulheres se faz mais severo diante de modelos de como o sujeito mulher deve se parecer - nunca se é bonita o suficiente, nunca se é mulher por inteiro. Essa compreensão é reafirmada pela matéria da Folha Feminina quando expressa que "Ser bela é dever de toda mulher, em qualquer idade. A boa aparência é imprescindível, não só em passeios e visitas, mas na rotina diária" (Folha do Norte do Paraná, Boa aparência não custa muito, 11 jul. 1964, p. 6.).

A cobrança pela beleza da mulher na mídia é indício de toda uma história cultural que, reforçada por discursos comerciais, define padrões aprendidos e compreendidos ontem e hoje. A "boa aparência feminina" como imperativo de valor na sociedade transparece na Folha Feminina. Aos homens - no FNP e, de maneira geral, nas mídias dos Anos Dourados (1945-1964) - parece não haver cobranças de cuidados com a beleza. Buitoni, que estudou amplamente a imprensa feminina nacional, concluiu: "para os homens, o poder concreto; para as mulheres, a imagem corporal" (BUITONI, 2009, p. 205). Os padrões estéticos, contudo, por si só, não reiteram automaticamente desigualdades, mas categorizações de gênero que impunham a beleza feminina como obrigatória para essa mulher dos anos 1960 apresentam-se, certamente, como dispositivos reguladores.

\section{A bela mulher, culta e que trabalha fora: nuances e transformações das representações}

As matérias que abordaram temas ligados às indicações de condutas "adequadas" às mulheres (10 publicações) e a temas relacionados à cultura (2 matérias), dentro do universo do corpus explorado, não são quantitativamente expressivas. No entanto, suas 
especificidades em vista do quadro geral da documentação identificada, instigou a colocá las em perspectiva, a fim de compreender nuances e transformações das representações sobre a mulher veiculadas na Folha Feminina.

Ao longo dos Anos Dourados, era comum ouvir que carreira e matrimônio eram inconciliáveis, mas em 1962, o Estatuto da Mulher Casada "reconhece finalmente a mulher como 'companheira e consorte', podendo 'colaborar' com o marido no orçamento familiar" (PINSKY, 2014, p. 210). Assim, trabalhar fora, para as mulheres, já não parecia mais uma possibilidade tão distante.

Pinsky, dessa forma, aponta que "os anos de 1945 a 1964 significam muito para a história do Brasil em geral e para as relações de gênero em particular" (PINSKY, 2014, p. 15). Explica a autora que as representações dos anos que compreendem essa época remetem a idealismos e, do ponto de vista econômico, o país ingressa em uma fase de desenvolvimento acelerado, em que a produção industrial e a urbanização vigoram rapidamente, de modo que o consumo passa a ser mais incentivado e a oferta de empregos urbanos cresce significativamente, refletindo no status socioeconômico feminino.

A própria região em que o FNP está inserido, nesse momento, está em fase de crescimento econômico, e o cenário urbano ainda está sendo desenhado. Apontamentos sobre história da imprensa regional confundem-se com o desenvolvimento da sociedade norte paranaense. As publicações do jornal nesse período, portanto, traduzem e elucidam noções e valores que, no campo social, estavam em destaque e eram vistas como desejáveis.

Nessa época, a década de 1960, algumas mudanças no cenário social despontam, como por exemplo, quando "a educação escolar de mulheres passa a ser mais valorizada ao lado das concepções arraigadas de que as mulheres devem dedicar-se preferencialmente ao lar e aos filhos" (PINSKY, 2014, p. 17). Del Priore (2014b) aponta que na revista Cláudia, nas matérias assinadas por Carmen da Silva nos anos $1960^{7}$, por exemplo, frequentemente se admitiam possibilidades para que a mulher se realizasse em outras funções que não as de mãe e dona de casa.

A Folha Feminina do FNP, ainda que tenha abordado esse conteúdo dentro de uma coluna na qual se dão essencialmente dicas de beleza, permite perceber que também admite essa possibilidade: "Você já reparou como nos filmes a jovem heroína aparece saindo do trabalho impecavelmente arrumada?", questiona a matéria "Palavras à môça que trabalha" (Folha do Norte do Paraná, 15 mar. 1963, p. 7). Ou ainda, "A boa aparência é uma das coisas importantes para a mulher que trabalha. Por isso, não deve faltar em sua bolsa um estojo de

\footnotetext{
${ }^{7}$ Apresentando-se como jornalista e escritora, Carmen fundamentava seus artigos na psicologia, tendo adquirido ampla reputação entre as leitoras, "tornando-se a 'pensadora' feminina (no que diz respeito a revistas de comunicação de massa) que mais influência teve” (BUITONI, 2009, p. 106).
} 
pó compacto para retocar a maquiagem", reafirma a matéria "Beleza no escritório" (Folha do Norte do Paraná, 19 ago. 1964, p. 6).

Vale lembrar que o FNP, no período aqui analisado, pertencia à Igreja Católica, tendo como editor chefe o bispo Dom Jaime Luiz Coelho. Essa particularidade requer atenção especial na análise das representações acerca da mulher neste período, uma vez que a "Igreja Católica, em uníssono com outras instituições conservadoras, [...] coloca restrições à dedicação aos estudos e à profissionalização das mulheres" (PINSKY, 2014, p. 178). A participação feminina no mercado de trabalho e no setor de consumo coletivo era, portanto, carregada de preconceitos, assim como os discursos que na época abordavam o tema.

Ainda assim, as reportagens do FNP apresentadas, mostram que, mesmo nos discursos de uma mídia impressa de posse da Igreja Católica, as mudanças sociais não eram ignoradas. As representações da mulher veiculadas, portanto, passam a expressar as transformações que vinham ocorrendo na própria sociedade, sem, contudo, deixar de lado a valorização da beleza como atributo feminino, como pode ser observado.

Nessa época, inclusive, o próprio Concílio do Vaticano II (1962-1965), evento de destaque para a Igreja Católica, já convidava a "olhar o mundo com simpatia e compreensão", pois nele:

Falava-se em paternidade responsável, em planificação familiar por meio de métodos naturais e muito importantes, em amor conjugal: o amor entre esposos como um bem incalculável para os filhos, a interação entre amor físico e espiritual e a renovação contínua do amor - uma agenda, sem dúvida, revolucionária e generosa para seu tempo (DEL PRIORE, 2014b, p. 75).

Além disso, na própria imprensa feminina, em nível nacional, na revista Cláudia, que surgiu nas bancas também nos anos 1960, a coluna "A arte de ser mulher", assinada pela jornalista Carmen da Silva, inaugurava publicações feministas, de modo que, para as mulheres, as informações da mídia começam a apontar possibilidades de subversões e indícios de formas de resistência possíveis à época (DEL PRIORE, 2014b). Tais mudanças, em grande parte, são acompanhadas pela "Igreja Católica [que] continua poderosa como orientadora de conduta, mas vai perdendo terreno para novas influências advindas dos meios de comunicação, do feminismo internacional e da educação laica" (PINSKY, 2014, p. 18). É evidente que no FNP essa relação é reduzida, pelo fato de que a própria mídia, nesse 
caso, tinha suas reportagens filtradas pelo crivo de uma linha editorial orientada pela Igreja, já que essa instituição tinha posse do veículo de comunicação.

Todavia, não podemos esquecer que, justamente na década de 1960, começam a surgir no Brasil discursos emancipatórios (de vários movimentos sociais, como o estudantil, negro, feminista, etc.), permitindo que houvesse e se fortalecessem personagens coletivos femininos e, portanto, públicos (MOTTA, 2012). E assim, mesmo os conteúdos das publicações femininas (como as da Folha do Norte do Paraná), ainda que não costumassem propor ideias revolucionárias e abrir caminhos, também não podiam distanciar-se demais das transformações que ocorriam na sociedade, arriscando desagradar o público leitor.

Mesmo sabendo que a Igreja Católica "permanece apegada a concepções conservadoras: prega a submissão da esposa ao marido, é contra o trabalho feminino fora do lar, proíbe a dissolução do casamento e critica duramente muitas das modificações que estão ocorrendo na sociedade" (PINSKY, 2014, p. 18), no FNP, notamos discursos que evidenciam aos pouco algumas transformações nas representações da mulher veiculadas, como quando as matérias elucidam, por exemplo, o fato de que mulheres que trabalham em escritório são comuns e, em certo momento, até as apresenta como belas moças admiráveis, como é o caso da matéria já citada "Palavras à môça que trabalha". O imperativo da beleza, contudo, aparece se apropriando de novos espaços, "acompanhando" a mulher, denotando que ela pode trabalhar fora do lar desde que não se esqueça dos cuidados com a beleza, tidos como essência de feminilidade.

Se o discurso da mulher no espaço público, "trabalhando fora", é bastante destacado nas matérias $^{8}$, a aquisição de cultura e conhecimentos por iniciativa feminina também foi um discurso presente (na matéria "Se quer ser bela, cultive-se", publicada em 5 de setembro de 1963 e republicada em 11 de março de 1964):

é preciso abrir-se às diversas expressões da cultura, conferências, música, leitura de livros de bons autores. Isso tudo a irão formando e apurando. Lembre-se, principalmente das exposições de pinturas. [...] tente, de tôdas as maneiras possíveis, criar um horizonte mais vasto do que o de sua casa ou o de seu trabalho [...] Trate de se informar sobre o

\footnotetext{
${ }^{8}$ Das 89 matérias referentes à temática da beleza, 5 fazem essa menção. A matéria "Palavras à moça que trabalha" (Folha do Norte do Paraná, 15 mar. 1963, p. 7) aponta que heroínas de filmes costumam sair do trabalho "impecavelmente" arrumadas e apresenta dicas para seguir esse exemplo. Em "Lindas mãos em poucos minutos" (Folha do Norte do Paraná, 30 jan. 1964, p. 6), ensina-se às datilógrafas como manter macia a pele das mãos. Já em "Você é responsável pelo seu rosto" (Folha do Norte do Paraná, 11 mar. 1964, p. 6), afirma-se queo lar, o estudo e o trabalho são preocupações frequentes de moças de 25 anos. A matéria "Segredos de beleza" (Folha do Norte do Paraná, 11 jun. 1964, p. 6) fala em como a vida agitada de muitas mulheres "dentro e fora do lar" pode causar rugas. Por fim, em "Beleza no escritório" (Folha do Norte do Paraná, 19 ago. 1964, p. 6), sustenta-se que manter-se bela e bem maquiada no ambiente do trabalho é essencial porque há a necessidade de causar boa impressão.
} 
que acontece no mundo. (Folha do Norte do Paraná, Se quer ser bela, cultive-se, 5 set. 1963, p. 7).

Essa matéria personifica um posicionamento diferenciado, uma vez que incentiva a mulher a olhar para além do lar, valorizando os conhecimentos, a cultura e a arte, que seriam também uma forma de ser e apresentar-se bela. Neste caso, é possível compreender que "a bagagem cultural (adquirida em leituras e no contato com peças de teatro, filmes e obras de arte) é valorizada principalmente em função da conquista amorosa" (PINSKY, 2014, p. 82). A cultura era tida não como satisfação pessoal ou contraversão dos moldes e limites impostos à mulher da época, justamente porque depois que a moça se casa "diplomas só servirão para vaidades", conforme ilustra Pinsky, comentando uma publicação da imprensa feminina nos Anos Dourados. Isso pode ser percebido na matéria do FNP intitulada "Você é responsável pelo seu rosto", que afirma que conforme a mulher amadurecia, "o trabalho, o lar, o estudo, as perguntas diante das interrogações vitais costumam passar para um plano mais importante. Esta aquisição [de] consciência vai definindo a beleza da mulher" (Folha do Norte do Paraná, Você é responsável pelo seu rosto, 11 mar. 1964, p. 6). O que se costumava afirmar era que, ainda que aceitável, a aquisição de saber, contudo, não podia sobrepor-se ao marido, evidentemente, pois "mulheres inteligentes e cultas eram incentivadas a ajudar os maridos, sem que este se sentisse humilhado" (DEL PRIORE, 2014a, p. 161).

Esses discursos que incentivam a educação feminina, principalmente na Folha Feminina do FNP, eram raros. Mas mesmo que a busca por cultura servisse para enriquecer as conversas e auxiliar nos relacionamentos amorosos, estes indícios apontam nuances nas representações historicamente associadas à mulher. Debruçar-se sobre o mundo da leitura, música e pintura era uma espécie de válvula de escape para a mulher dos Anos Dourados. Del Priore (2014b, p. 108) comenta que, entre as elites, cantar e tocar piano eram conselhos dados às mulheres pela imprensa: "Nos anos 1960, quando uma mulher honesta falava em prazer, já se sabia: só podia estar falando de satisfações espirituais, como arte, literatura, contemplação da paisagem".

Essas representações revelam como as mensagens podem ser ao mesmo tempo reiteradoras e contraditórias. Justamente por isso, não compreendemos os discursos do FNP como verdadeiros, mas admitimos que há, nas representações ali presentes, uma força social das percepções do mundo que a elas confere uma versão legítima que pode dialetizar com a realidade.

Assim como indicam Matos e Lopes (2008), compreendemos que estas não são apenas veiculadas pela mídia, mas também são nela produzidas. Por meio dos discursos que circulam nos textos e imagens sobre embelezamento, produzem-se efeitos e instituem-se "verdades", excluindo e incluindo corpos, sujeitos e grupos, direcionando a atuação destes 
na sociedade. Isso acontece porque, para fidelizar as leitoras, as publicações femininas tentam refletir um aparente consenso social, divulgando ideais de mulheres e homens que, embora sejam socialmente construídos, apresentam-se como naturais, universais e irremovíveis (PINSKY, 2014).

A Folha Feminina, ao mesmo tempo em que fala para mulheres de classe média urbana, difunde ideias e cunha modelos a serem seguidos dentro deste padrão existencial. Notamos como os elementos que perpassaram as matérias da coluna feminina do FNP, como as relações entre mulher e beleza, embora múltiplas, trabalham para naturalizar a relação entre ambas, para normatizar o corpo e moralizar o comportamento da mulher; como procuram manter um modelo que já vem de séculos passados, reiterando desigualdades. Estas concepções, ao mesmo tempo, vão se apropriando de elementos e aspectos que passam a emergir no contexto da década de 1960, expressando normas e também mudanças em curso.

As condutas tidas como aceitáveis legitimavam comportamentos femininos desejados, ensinando como polir o "verniz" social que se esperava que as mulheres possuíssem. As breves menções ao acesso à cultura e aos novos espaços (nos escritórios e escolas, por exemplo), ainda assim, relembravam que mesmo que as mulheres ocupassem novos ambientes, não poderiam esquecer-se de que na beleza se ancorava a feminilidade, e buscála era tarefa constante.

\section{Considerações finais}

Por mais que tenha desempenhado notável relação de poder por sua representatividade midiática regional, o jornal Folha do Norte do Paraná não teve a capacidade de sozinho determinar padrões irredutíveis. Assim, é possível afirmar que as leitoras da coluna feminina nem sempre agiram de acordo com as representações construídas neste espaço. Do mesmo modo, as representações veiculadas em tal mídia nem sempre acompanharam as mudanças sociais em curso.

A discussão do presente texto pautou a temática da beleza de mulher, sob o enfoque dos estudos de gênero, das representações sociais e das relações de poder, em uma direção que observou múltiplas relações perpassadas pela cultura, em um movimento de antagonismos e complementaridades. Estudar as relações de gênero presentes no FNP foi, desde o início, um movimento dialético e dialógico. 
O FNP constituiu-se em um recurso utilizado pela Igreja Católica no intuito de estabelecer diretrizes com base nos princípios defendidos pela instituição. Junto aos discursos que permitem notar algumas mudanças, são eminentes aqueles que seguem os modelos bíblicos de homem e mulher tradicionalmente hierarquizados, os quais estão presentes nas percepções da Igreja, e de alguma forma na linha editorial do FNP, de modo que é possível afirmar que o jornal se constituiu como instrumento de consolidação de conviç̧ões da instituição no meio jornalístico regional.

A pesquisa dessa mídia impressa, desse modo, permitiu um olhar para a esfera da cultura, possibilitando a compreensão de valores, crenças e práticas que permearam as relações sociais do período investigado. Ao utilizar o jornal como fonte, assim, é preciso pensar sua inserção histórica enquanto força ativa, já que este não só registra os acontecimentos, mas também faz parte dos processos que os geram, atuando na constituição de modos de vida, de perspectivas e da consciência histórica (DARNTON, 1990).

Quando tratamos da transmissão de informação midiática, ainda, deixamos claro que esta não pode ser compreendida como linear, ou mesmo em um modelo de comportamento condicionado por meio do estímulo-resposta, capaz de criar a ilusão de uma absorção automática da informação. Não se trata, assim, de uma compreensão orientada pelo superado modelo da teoria hipodérmica (ou teoria da bala mágica), em que há a noção limitada de injeção ou disparo de comunicação de massa sem resistência da parte dos receptores (WOLF, 1999).

A beleza e a coquetteire ancoraram a feminilidade nas representações construídas no FNP e didatizaram as formas de expressar-se para o mundo, apresentando dicas, regras e exigências. Mas mudanças e nuances nos modelos homogeneizantes fizeram-se presentes em determinadas representações que, às vezes, admitiam a presença feminina em espaços pouco comuns até então, tais como o mercado de trabalho, além da valorização dos conhecimentos, da cultura e da arte.

Entendemos que concessões aos modelos rígidos foram estimuladas pelo contexto social da época, com o início da incorporação de pautas feministas nas discussões, mas também foram permitidas por flexibilidades da própria instituição que administrava o FNP, fundamentadas no que também se discutia no âmbito do Concílio do Vaticano II, por exemplo.

A Folha do Norte do Paraná,, entretanto, muito longe da vanguarda nesses assuntos, deu espaço apenas ao que considerou pertinente conforme sua política editorial, e talvez motivado por demandas do leitor. A Folha Feminina, neste caso, não retratou muitas mudanças e não discutiu novidades sociais. No icônico ano de 1964, momento político pelo qual o país passava quando se instaura o regime militar, por exemplo, a coluna feminina não faz menção alguma ao assunto, subentendendo-se possivelmente que não era 
considerado, pela editoria, como um "assunto feminino". Não há, nas matérias, indícios de discussões de atualidades, talvez porque, nestes espaços, conforme antecipou Buitoni "o jornalismo feminino já nasceu complementar, revestido de um caráter secundário, tendo como função o entretenimento e, no máximo, um utilitarismo prático ou didático" (BUITONI, 2009, p. 30).

Contudo, em uma época de instabilidade e (re)formulações de condutas e de normas de gênero, como foram os anos de 1960, não há como uma publicação tal qual a Folha Feminina, direcionada ao público feminino, manter um posicionamento impenetrável. Por isso, buscamos evidenciar de que modo, por vezes, algumas representações acabaram sendo influenciadas pelas mudanças sociais da época.

Por este motivo, é pertinente, com base nessas conclusões, não se descolar do contexto histórico e social, imbuído das dinâmicas multiespaciais - local, regional, nacional e mundial - já que tanto o FNP como o período analisado têm peculiaridades próprias que lhes conferem muitas especificidades. Os estudos da mídia impressa como fonte e objeto de pesquisa, assim como os estudos de gênero que avaliam representações femininas, não podem ser considerados concluídos, pois eles renovam-se a cada nova consulta, em um movimento de (des)construção de sentidos que não tem começo e nem fim determinado.

\section{Fontes Documentais}

Folha do Norte do Paraná. A beleza antes de tudo, 22 mar. 1964, p. 6.

Folha do Norte do Paraná. Afinal como ser bela?, 17 abr. 1964, p. 5.

Folha do Norte do Paraná. Maneiras à mesa, 3 jul. 1964, p. 6.

Folha do Norte do Paraná. Para sua beleza, 3 jul. 1964, p. 6.

Folha do Norte do Paraná. Boa aparência não custa muito, 11 jul. 1964, p. 6.

Folha do Norte do Paraná. Palavras à môça que trabalha, 15 mar. 1963, p. 7.

Folha do Norte do Paraná. Beleza no escritório, 19 ago. 1964, p. 6.

Folha do Norte do Paraná. Se quer ser bela, cultive-se, 5 set. 1963, p. 7.

Folha do Norte do Paraná. Você é responsável pelo seu rosto, 11 mar. 1964, p. 6. 


\section{Referências}

ALMEIDA, Angela Maria Menezes de. Feminilidade: caminho de subjetivação. Estudos de Psicanálise, Belo Horizonte, v. 4, n. 38, p. 29-44, 2012.

ALVES, Fábio Lopes. Pós-mulher: corpo, gênero e sedução. Curitiba: Editora Champagnat, 2014.

BARDIN, Laurence. Análise de conteúdo. São Paulo: Edições 70, 2011.

BARROS, Clarissa Dubeux. A beleza e a feiura na contemporaneidade. Diálogos, Garanhuns, v. 9, p. 73-86, maio/jun. 2013.

BEAUVOIR, Simone de. O segundo sexo. Rio de Janeiro: Nova Fronteira, 1980. v. 1.

BUITONI, Dulcília Schroeder. Mulher de papel: a representação da mulher pela imprensa feminina brasileira. São Paulo: Summus, 2009.

CHARTIER, Roger. O mundo como representação. Revista Estudos Avançados, São Paulo, v. 5, n. 11, p. 173-191, 1991.

COURTINE, Jean-Jacques; HAROCHE, Claudine. História do rosto: exprimir e calar as suas emoções (do século XVI ao início do século XIX). Lisboa: Teorema, 1988.

DARNTON, Robert. O beijo de Lamourette: mídia, cultura e revolução. São Paulo: Companhia das Letras, 1990.

DEL PRIORE, Mary. Corpo a corpo com a mulher: pequena história das transformações do corpo feminino no Brasil. São Paulo: Senac, 2009.

DEL PRIORE, Mary. Histórias e conversas de mulher: amor, sexo, casamento e trabalho em mais de 200 anos de história. São Paulo: Planeta, 2014a.

DEL PRIORE, Mary. Histórias intimas: sexualidade e erotismo na história do Brasil. São Paulo: Planeta, 2014b.

ECO, Umberto. História da beleza. Rio de Janeiro: Record, 2004. 
GARUTTI, Selson. O poder do anel na diocese de Maringá. Ciências da religião: história e sociedade, São Paulo, v. 11, n. 1, p. 65-88, 2013.

MATOS, Auxiliadôra Aparecida de; LOPES; Maria de Fátima. Corpo e gênero: uma análise da revista TRIP Para Mulher. Revista Estudos Feministas, Florianópolis, v. 16, n. 1, p. 61-76, 2008.

MOTTA, Alda Britto da. Mulheres velhas: elas começam a aparecer. In: PINSKY, Carla Bassanezi; PEDRO, Joana Maria (Org.). Nova história das mulheres no Brasil. São Paulo: Contexto, 2012. p. 84-103.

PÁTARO, Cristina Satiê de Oliveira; MEZZOMO, Frank Antonio; RIBEIRO, Amanda de Souza. Mãe, esposa e dona do lar: representações da mulher no Jornal Folha do Norte do Paraná. Fênix: Revista de História e Estudos Culturais, Uberlândia, v. 11, p. 1-23, 2014.

PÁTARO, Cristina Satiê de Oliveira; MEZZOMO, Frank Antonio; SILVA, Géssica Aline. No lar e na família: permanência e mudanças nas representações da mulher face aos ventos modernizantes. Educere et Educare, Cascavel, v. 9, p. 269-281, 2014.

PAULA, Antonio Roberto de. O jornal do bispo: a história da Folha do Norte do Paraná: o primeiro livro online de Maringá. Maringá, 2009. Disponível em: <jornaldobispo.blogspot.com>. Acesso em: 10 out. 2016.

PINSKY, Carla Bassanezi. Mulheres dos anos dourados. São Paulo: Contexto, 2014.

ROBLES, Orivaldo. A igreja que brotou da mata: os 50 anos da Diocese de Maringá. Maringá: Dental Press Editora, 2007.

RUBINO, Carla. Difusão da fé e sua mobilidade religiosa em Maringá: 1947 a 2010. 126f. Dissertação (Mestrado em Geografia) - Universidade Estadual de Maringá, 2010.

SANT'ANNA, Denise Bernuzzi de. Corpo e beleza: "sempre bela". In: PINSKY, Carla Bassanezi; PEDRO, Joana Maria (Org.). Nova história das mulheres no Brasil. São Paulo: Contexto, 2012. p. 105-125.

SILVA, Márcia Pereira Silva; FRANCO, Gilmara Yoshihara. Imprensa e política no Brasil: considerações sobre o uso do jornal como fonte de pesquisa histórica. Revista História em Reflexão, Dourados, v. 4, n. 8, p.1-11, jul./dez. 2010.

SKURA, Ivânia; PÁTARO, Cristina Satiê de Oliveira; MEZZOMO, Frank Antonio. Relações de gênero e estereótipos femininos em anúncios de ontem e de hoje. História, histórias, Brasília, v. 3, p. 79-97, 2015.

SOIHET, Rachel; PEDRO, Joana Maria. A emergência da pesquisa da História das Mulheres e das Relações de Gênero. Revista Brasileira de História, São Paulo, v. 27, n. 54, p. 281-300, 2007. 


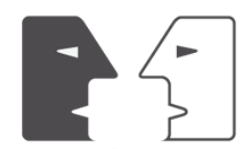

ANTÍTESES

TAIT, Tania Fatima Calvi. As excluídas da história: o olhar feminino sobre a formação de Maringá, In: DIAS, Reginaldo Benedito; GONÇALVES, José Henrique Rollo. Maringá e o Norte do Paraná: estudos de história regional. Maringá: Eduem, 1999. p. 351-169.

VILHENA, Junia de; MEDEIROS, Sergio. A violência da imagem: estética, feminino e contemporaneidade. Revista Mal-Estar e Subjetividade, Fortaleza, v. 5, n. 1, p. 109-144, 2005.

WOLF, Mauro. Teorias da comunicação. Lisboa: Presença, 1999.

WOLF, Naomi. O mito da beleza: como as imagens de beleza são usadas contra as mulheres. Rio de Janeiro: Rocco, 1992.

Recebido em 16/10/2016

Aprovado em 12/05/2017 